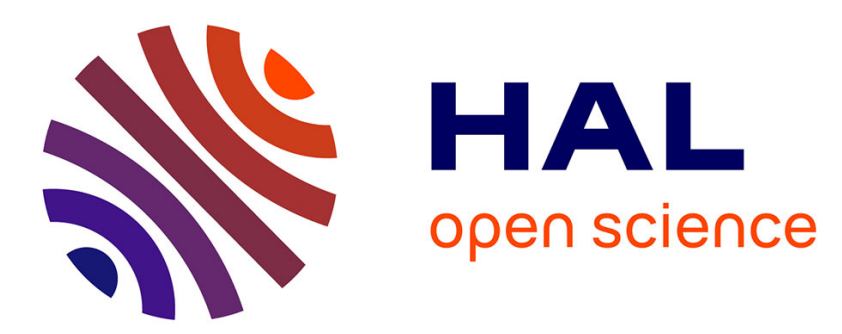

\title{
The Effect of Competing Intentions and Behaviour on Short-Term Childbearing Intentions and Subsequent Childbearing
}

Dimiter Philipov

\section{- To cite this version:}

Dimiter Philipov. The Effect of Competing Intentions and Behaviour on Short-Term Childbearing Intentions and Subsequent Childbearing. European Journal of Population / Revue européenne de Démographie, 2009, 25 (4), pp.525-548. 10.1007/s10680-009-9197-7 . hal-00535480

\author{
HAL Id: hal-00535480 \\ https://hal.science/hal-00535480
}

Submitted on 11 Nov 2010

HAL is a multi-disciplinary open access archive for the deposit and dissemination of scientific research documents, whether they are published or not. The documents may come from teaching and research institutions in France or abroad, or from public or private research centers.
L'archive ouverte pluridisciplinaire HAL, est destinée au dépôt et à la diffusion de documents scientifiques de niveau recherche, publiés ou non, émanant des établissements d'enseignement et de recherche français ou étrangers, des laboratoires publics ou privés. 


\title{
The Effect of Competing Intentions and Behaviour on Short-Term Childbearing Intentions and Subsequent Childbearing
}

\author{
L'effet des intentions et des comportements concurrents sur les \\ intentions de procréation à court terme et la procréation \\ ultérieure
}

\section{Dimiter Philipov}

Received: 20 March 2009/Accepted: 31 July 2009/Published online: 12 November 2009

(C) Springer Science+Business Media B.V. 2009

\begin{abstract}
This article examines the effect that intentions to start studying and to enter into employment may have on childbearing intentions and subsequent childbearing. The analysis also includes the impact of the corresponding behaviour: currently studying or being employed. The theoretical background draws on Barber's study of competing attitudes, with an emphasis on competing intentions. Based on survey and register data for Bulgaria, the analyses reveal the effect of competing intentions. For example, the intention to start studying hampers the construction and subsequent realisation of intentions to have a child within 2 years. The actual behaviour of currently studying has the same effect; both effects are most pronounced for intentions to become a parent and for actual entry into parenthood. Inversely, an intention to enter into employment facilitates childbearing intentions and, for men, so does the behaviour of being employed. The latter result holds for women's intention to have a second child. The findings indicate that when childbearing intentions and realisation are analysed, it is preferable to consider persons with a competing intention to start studying either as a separate group or group them with those who are currently studying, not with those who are not. Logistic regression models and interaction effects are applied for the analyses.
\end{abstract}

Keywords Childbearing intentions - Fertility intentions - Competing intentions · Realisation of intentions - Competing attitudes · Fertility behaviour

Résumé Cet article examine l'effet que l'intention de commencer des études et l'intention d'entrer dans la vie active peuvent exercer sur les intentions de

D. Philipov ( $\square)$

Vienna Institute of Demography, Wohllebengasse 12-14, 1040 Vienna, Austria

e-mail: dimiter.philipov@oeaw.ac.at 
procréation et la procréation ultérieure. L'analyse tient compte également de l'impact du comportement correspondant : être en cours de scolarité, ou être en situation emploi. Le cadre théorique s'appuie sur l'étude par Barber des attitudes concurrentes, et met l'accent sur les intentions concurrentes. A partir de données d'enquêtes et d'état civil rassemblées en Bulgarie, les analyses menées révèlent l'effet des intentions concurrentes. Par exemple, l'intention de commencer des études entrave la construction et la réalisation ultérieure des intentions d'avoir un enfant dans les deux années à venir. Il en est de même pour le fait de d'être en cours de scolarité. Les deux effets sont le plus prononcés pour l'intention de devenir parent et pour l'entrée dans la parentalité. A l'opposé, l'intention d'entrer dans la vie active favorise les intentions de procréation, et, pour les hommes, il en est de même pour le fait d'être en situation d'emploi. Pour les femmes, être en situation d'emploi favorise l'intention d'avoir un second enfant. Tout ceci indique que pour analyser les intentions de procréation et la réalisation de ces intentions, il est préférable d'étudier séparément les personnes ayant exprimé l'intention concurrente de commencer des études, ou de les grouper avec celles qui sont en cours de scolarité, plutôt qu'avec celles qui ne le sont pas. Des modèles de régression logistique et des effets d'interaction ont été mis en œuvre dans les analyses.

Mots-clés Intentions de procréation - Intentions de fécondité ·

Intentions concurrentes - Réalisation des intentions - Comportement de fécondité

\section{Introduction}

The recent decline in fertility has prompted increased interest among demographers wishing to develop a better understanding of childbearing intentions. Indeed, recent studies report intentions as a powerful predictor of fertility at the aggregate population level (Quesnel-Vallée and Morgan, 2003; Liefbroer 2009; Testa and Toulemon 2006; Symeonidou 2000). Yet at the individual level, intentions are frequently 'missing the target' (Quesnel-Vallée and Morgan 2003), as the above-cited and other authors indicate. There is unanimous agreement among scholars that intentions may remain unrealised because of the inhibiting effect that external circumstances may exert during the period from the formation of intentions until their realisation. Conflicting roles that young adults face in their life, such as being in education, starting a working career, acquiring a house, are among the main obstacles to the fulfilment of childbearing intentions. For example, Thomson and Brandreth (1995) stress the importance of the centrality of fertility desires in comparison with other life goals (p. 82); Schoen et al. (1999) note that '...entries into and exits from both education and employment-are among the external constraints over which individuals have limited control. Those events are likely to have profound effects on the translation of fertility intentions into actual behaviour...' (p. 791).

The interdependency of life paths related to education, working career, family formation and childbearing is widely reflected in studies on actual fertility. Like 
behavioural outcomes in different life paths, the corresponding intentions can be interdependent in the sense that they either compete with or facilitate each other. The question then arises: if actual competing behaviour may impede the realisation of fertility intentions, what is the effect of intentions to perform a competing behaviour on childbearing intentions? Surprisingly, this topic has not been addressed by researchers so far.

This article examines the effect that intentions to take up studies and the intention to enter into employment may have on childbearing intentions and subsequent childbearing. The analysis includes also the impact of the corresponding behaviour: currently studying or being employed. The theoretical background draws on the inclusion of the impact of competing attitudes in the theory of planned behaviour (TPB) (Ajzen 1991), due to Barber (2001; see also Barber et al. 2002 or Barber and Axinn 2005). While Barber applied her theory to study the effect of competing attitudes, I explore the effect of competing intentions on childbearing intentions and their realisation. The analyses also include tests of the effect of competing behaviours on childbearing when the intermediary role of intentions is surpassed. I also analyse the effect of the relevant competing behaviours on childbearing intentions and their realisation. The empirical analysis rests on data from a survey carried out in Bulgaria in 2002, complemented with information about births during the subsequent 3 years from the civil registration system. The focus is explicitly on short-term intentions, defined with respect to having a child within the next 2 years.

The main findings indicate that intentions to start studying, or the behaviour of actually studying, hamper the realisation of childbearing intentions. In the Bulgarian context, the intention to enter into employment, or actually being employed, facilitates the realisation of childbearing intentions. These inferences indicate that to better understand fertility intentions and subsequent childbearing it might be insufficient to search for explanatory variables based on the actual behaviour while disregarding the relevant intentions. For example, the findings in this article indicate that it is preferable to include a contrast between persons who are neither studying nor intend to do so and persons who are studying or have the intention to take up studies, rather than having a contrast between those who are studying and those who are not.

\section{Theoretical Background}

Young adult life is dense with crucial events that have long-term implications. The demographic component of the life course at these ages includes entry into union, frequently in the form of a cohabitation that soon turns into a marriage, the birth of one's first child, dissolution of a union, etc. Other important events and processes include leaving the parental home and settling in a separate dwelling with the prospect of acquiring a dwelling of one's own, completion of education preceded by a choice of a specific qualification, entry into employment and organising and managing one's own working career. Recent technological change and globalisation make these processes more complicated and diversified, requiring more time and resources (Blossfeld et al. 2005). As a consequence, they exercise an increasing 
competition for the use of individuals' time and resources. For example, childrearing, studying and employment require time, summing up to a total that is larger than the time which is physically available to an individual. Thus, childrearing, education and employment are in fact competing for an individual's time. The incompatibility, or conflict, of the roles of being a parent, a student and a worker is seen today as one of the main reasons for the decline and postponement of fertility observed in all developed countries. Where European studies are considered, Corijn and Klijzing (2001) and Blossfeld et al. (2005) provide collections of international comparative studies on this topic and the European Journal of Population had a special issue (Gauthier 2007). Rindfuss and BraunerOtto (2008) present a relevant general discussion.

Time incompatibility can be resolved by a sequential ordering of the events one after the other, i.e. some events being postponed until later. One example of the ordering of events is the sequence of completion of education followed by a first birth. This sequence is based on the expectation that a young person who is studying does not have the material resources, nor sufficient time, to care responsibly for his or her child, and the plausibility of this assumption has invoked the prevalence of social norms that accept a postponement of births until after the end of education (Blossfeld and Huinink 1991).

The way individuals organise their life course may depend on the welfare system, as well as on the prevalent culture and recent ideational changes. For example, Billari and Philipov (2004) showed that completion of education precedes first births in a less pronounced manner in the Nordic countries where a universalistic welfare regime prevails, as compared to the conservative, liberal and southern European welfare regimes (see Esping-Andersen 1999, for definitions of the universalistic, conservative and liberal welfare regimes; Anttonen and Sipilä 1996, for the southern European welfare regime).

The organisation of one's own life course implies the existence of a decisionmaking process (Blossfeld et al. 2005, p. 16ff., consider its rationality and discuss the impact of uncertainty). Intentions are a main component of the decision whether to perform or to avoid certain behaviour; therefore, the better we understand intentions the better we will be able to understand the corresponding behaviour. The TPB (Ajzen 1991; Ajzen and Fishbein 2005) has been applied successfully in a number of demographic studies and for the analysis of fertility intentions in Bulgaria (Billari et al. 2009). In short, this theory states that intentions are defined by three main groups of factors. The first group includes positive and negative attitudes towards experiencing the behaviour in question (in our case, attitudes towards having a child within 2 years, independently of whether the person really wants to have a child or not). The second group includes the impact that friends or relatives (important others) may have on the person with respect to having a child. It is a measure of perceived norms formed under the influence of social pressure. The third group, perceived behavioural control, includes factors that describe the extent to which persons can exercise control over factors that have a major influence on the behaviour. The three groups are shaped by corresponding beliefs about the items included in the groups, and the latter are influenced by background factors such as age, sex, union status, level of education, income, emotions, values, religiosity, etc. 
Billari et al. (2009) provide a more detailed discussion. They found that the three blocks of factors exercise a significant effect on the formation of intentions to have a child within 2 years, specified by sex and parity. In their study, an intention to have a child was defined as a short-term intention: to have a child within the next 2 years. In this study, the same definition is applied as the same data set is used.

Barber (2001) expanded the TPB to include the impact of attitudes related to competing behaviours, which she called competing attitudes. She examined the effect of attitudes towards such competing behaviours as educational attainment, career development and consumer spending, on childbearing. Barber (2001, Fig. 1) considers a block of competing attitudes as an external factor which has an effect on childbearing attitudes, on childbearing intentions and on the path from childbearing intentions to actual behaviour. Using US data from an eight-wave study, she examined the links between attitudes towards childbearing and towards competing behaviours and found significant support for the inclusion of competing attitudes in the study of childbearing decision making and behaviour. The data made it possible to study long-term intentions for having children. Extending her approach, Moors (2008) investigated a latent class of attitudes towards childbearing; his analysis also centres on competing attitudes rather than on competing intentions.

While competing attitudes influence attitudes towards childbearing, it is premature to deduce that the corresponding competing intentions will influence childbearing intentions. Indeed, since attitudes are only one of the three antecedents of intentions, the effect of attitudes on subsequent childbearing need not imply the same effect of intentions. The Bulgarian study of the TPB (Billari et al. 2009) showed that subjective norms outweigh the other two components of the intentions where entry into parenthood is considered. For example, consider a woman who has positive attitudes towards becoming a mother while studying. Her close relatives and friends may discourage her and hence the impact of subjective norms on her intentions to have a child can be negative and outweigh the positive effect of her attitudes; the final outcome can be that the childbearing intention will be to not have a child before the completion of her studies.

According to the TPB, an intention to perform another behaviour (such as to start studying) is an external factor that may influence the intention to have a child. In analogy to Barber's framework for the attitudes, an external intention is competing with the intention of interest, in that it may have an effect on its formation as well as on the path towards its realisation. These links are presented graphically in Fig. 1. Line (g) presents the impact of intentions to perform an alternative behaviour on childbearing intentions, and Line (h) shows the impact that an intention to an alternative behaviour may have on the path from the childbearing intention to childbearing [Lines $(\mathrm{g})$ and $(\mathrm{h})$ correspond to the same lines in Barber's Fig. 1; her Lines (a)-(f) are not used in this article].

Consider the first case: when external intentions have an impact on the construction of childbearing intentions (Line g). Suppose that a woman wants both to have a child without postponement and to start studying without postponement. In this case, she knows she will face the conflict of roles of being a mother and a student at the same time and the subsequent problems of allocation of time and restricted resources. This conflict raises a cognitive dissonance (Festinger 1957) 


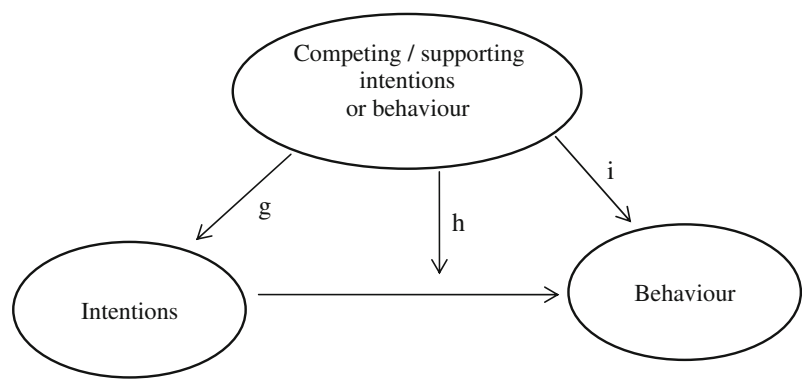

Fig. 1 Schematic presentation of the impact of competing or supporting intentions and behaviour (after Barber 2001, Fig. 1)

which she can resolve by constructing non-competitive intentions, such as to start studying now and postpone childbearing for later years, i.e. order events through life. In this case, the person is expected to construct an intention to start studying and an intention not to have a child within 2 years.

The second case (Line h) arises typically when a woman constructs two (or more) competing intentions and looks forward to their realisation. On the path towards realising them, she will face cognitive dissonance and will be expected to change one of the intentions, preferably the one which corresponds to a more crucial and irreversible behavioural outcome, such as having a child rather than starting her studies. In this second case, intentions actually compete for their realisation. According to the TPB, a preference for the realisation of one of the competing intentions depends on how strong the intentions are. The stronger the intention to have a child, the higher the chances that it will be realised, at one and the same level of the other intention.

Barber (2001) and Barber and Axinn (2005) empirically examined the relations between competing attitudes and consequent behaviour. The contribution of this article is in the empirical exploration of intentions, rather than their antecedents. I also discuss one addition to Barber's theoretical framework. It refers to the impact that competing intentions may have on actual behaviour surpassing the intentions of interest. In our case, this is the direct impact of intending to start studying, or intending to enter into employment, on subsequent childbearing. This link is represented by Line (i) in Fig. 1.

Beside competing intentions, I also examine the impact of the actual competing behaviours (currently studying or being employed) on childbearing intentions and their realisation. In the empirical analysis that follows I consider the alternative behaviour as an external factor to the construction and realisation of childbearing intentions, like the alternative intentions. For the sake of simplicity in the presentation, intentions and behaviour are included in the same block in Fig. 1 and Lines (g), (h), and (i) refer to each one of them. The inclusion of an external behaviour in this way can be argued from the point of view of the TPB, because it can be considered as a background factor to the three antecedent blocks (Fig. 1 in Billari et al. 2009) and thus it can influence intentions through attitudes, subjective norms or perceived behavioural control. Still, the impact of an alternative behaviour 
can be examined along Lines (g) or (h), because the three antecedent factors may fail to fully capture its impact as a background factor because of, for example, improper measurement. Moreover, there is a discussion within the TPB that some background factors may have their own direct influence on intentions and on the path towards the corresponding behaviour, surpassing the antecedent factors (Ajzen and Fishbein 2005). Hence, in either case, it is useful to carry out an empirical study of the impact of alternative behaviour on the formation and realisation of childbearing intentions along Lines ( $g$ ) and (h). The link between behaviours presented by Line (i) is not new in demography; for example, it has been studied in detail by Schoen et al. (1999).

\section{Contextual Environment: Bulgaria}

Before the start of the transition in 1989, the life course of young adults in Bulgaria was pretty standardised. The restrictive totalitarian regime did not leave many choices to young people; by nature of the regime, work should be available for everyone; salaries did not differ much; housing in the cities was distributed according to specific rules. Entering into a marriage and parenthood occurred at a young age: during the 1980s, the mean age of entry into motherhood was about 21.8 years, one of the lowest in Europe. A well-developed system of crèches and kindergartens, along with the traditional support of grandparents, made it possible to reconcile parenthood and other activities such as studying or being employed. Incompatibility between diverse roles was not as pronounced as in other European countries.

After the start of the transition and up to 2002, the situation changed radically. Unemployment emerged and expanded; in 2002, it was around 15\%, and considerably higher for young adults (higher than $25 \%$ for young women and $20 \%$ for young men). Jobs became less secure in an expanding free labour market. Wage levels diversified and frequently did not match the acquired qualification which led to relative deprivation. The rise and spread of a free market called for new professions and higher qualifications, and as a consequence educational enrolment was increased. During the privatization process, numerous kindergartens were closed since the houses had to be returned to their owners. The government was unable to support the population policy as it did in the past. Uncertainty increased. As a result, demographic events were postponed or foregone. In 2002, the mean age of entry into motherhood was 23.9 years, up from 21.8 in 1988, and the first-order total fertility rate was 0.69 , down from 0.92 in 1988. Universality of entry into marriage and parenthood vanished. Philipov et al. (2006) and Koytcheva and Philipov (2008) give more details about recent demographic changes and their explanations. These sweeping changes did not preserve the standardisation of the life course; it differentiated considerably and incompatibility of roles increased significantly. In the beginning of the twenty-first century, Bulgarian young adults experience the same problems of uncertainty in their life paths and incompatibility of roles as their western European coevals (Koytcheva 2006). 
Although in a typical family, both the man and the woman work for pay, the woman does most of the household chores. The duality of women's roles is considered as one important reason for the decline in fertility (Koytcheva 2006).

\section{Hypotheses}

The theoretical argumentation outlined above can be summarised in the following statements where short-term childbearing intentions refer to a period of 2 years, which is in line with the available data:

(i) A competing intention or behaviour hampers the construction of an intention to have a child within 2 years. A supporting intention or behaviour facilitates the construction of intentions to have a child.

These statements refer to Line (g) in Fig. 1.

(ii) An intention to have a child within 2 years is less likely to be realised when the individual intends to perform, or performs, a competing behaviour within the same period of time. A stronger intention to have a child within 2 years is less likely to be influenced by a competing intention or a competing behaviour as compared to a weaker intention.

An intention to have a child within 2 years is more likely to be realised when the individual intends to perform, or performs, a supporting behaviour within the same period of time. A stronger intention to have a child within 2 years is more likely to be influenced by a supporting intention or behaviour as compared to a weaker intention.

These two statements refer to Line (h) in Fig. 1.

(iii) A competing intention or behaviour hampers childbearing; a supporting intention or behaviour facilitates childbearing.

This statement refers to Line (i) in Fig. 1.

The main research task in this article is to test the hypotheses derived from these three statements when competing or supporting intentions and behaviour refer to the states of studying or employment. The hypotheses are derived under the prevailing conditions in Bulgaria.

A vast body of literature identifies studying as competing behaviour to childbearing. There is no reason to consider Bulgaria as an exception. Therefore, the above statements can be specified for the case of intentions to start studying, or currently studying, as follows:

(1A) An intention to start studying hampers the construction of an intention to have a child within 2 years.

(1B) Studying is a behaviour which hampers the construction of an intention to have a child within the next 2 years.

(2A) An intention to have a child within 2 years is less likely to be realised when the individual intends to start studying within the same period of time. A stronger 
intention to have a child within 2 years is less likely to be influenced by an intention to start studying, as compared to a weaker intention.

(2B) An intention to have a child within 2 years is less likely to be realised when the individual is in the state of studying at the time of the formation of intentions. A stronger intention to have a child within 2 years is less likely to be influenced by being in a study course, as compared to a weaker intention.

(3A) An intention to start studying hampers childbearing within 2 years.

(3B) Studying is a behaviour which hampers childbearing within the next 2 years.

The three pairs of hypotheses are expected to hold for men as well as for women.

Building hypotheses for the intention to enter into employment and for the behaviour of being employed is not straightforward for men and women because of the differences in gender roles. When men work, their income supports the family and therefore it is a supporting, not competing, behaviour with respect to childbearing. Men's opportunity costs are low in Bulgaria because of the prevalence of traditional gender roles in the family: men do less household work than women. Hence men's intentions to enter into employment can be considered as supporting, not competing, with childbearing intentions. Most women usually work for pay and at the same time do most of the household chores; so their opportunity costs are high. Hence for women, intentions to enter employment or being actually employed compete with the intention of having a child. The hypotheses for men and women therefore differ:

(4A) For men, an intention to enter into employment facilitates the construction of an intention to have a child within 2 years;

For women, an intention to enter into employment hampers the construction of an intention to have a child within 2 years.

(4B) For men, being employed facilitates the construction of an intention to have a child within the next 2 years;

For women, being employed hampers the construction of an intention to have a child within the next 2 years.

(5A) For men, an intention to have a child within 2 years is more likely to be realised when the man intends to enter into employment within the same period of time. A stronger intention to have a child within 2 years is more likely to be influenced by an intention to enter into employment as compared to a weaker intention;

For women, an intention to have a child within 2 years is less likely to be realised when the woman intends to enter into employment within the same period of time. A stronger intention to have a child within 2 years is less likely to be influenced by an intention to enter into employment as compared to a weaker intention.

(5B) For men, an intention to have a child within 2 years is more likely to be realised when the man is employed at the time of the formation of intentions. A stronger intention to have a child within 2 years is more likely to be influenced by being employed as compared to a weaker intention.

For women, an intention to have a child within 2 years is less likely to be realised when the woman is employed at the time of formation of intentions. A stronger 
intention to have a child within 2 years is less likely to be influenced by being employed as compared to a weaker intention.

(6A) For men, an intention to enter into employment facilitates childbearing within 2 years;

For women, an intention to enter into employment hampers childbearing within 2 years.

(6B) For men, being employed facilitates childbearing within the next 2 years; For women, being employed hampers childbearing within the next 2 years.

Women's opportunity costs can be compensated by various factors, such as expected support by parents or grandparents in childrearing; child allowances or maternal leave could be attractive particularly to women with lower incomes; nonemployed women may decide to enter into employment before the childbirth to get higher child allowances. In these and similar situations, employment may emerge as a facilitating rather than competing intention or behaviour.

\section{Data and Methods}

I use data from a survey in Bulgaria, carried out in 2002 with the purpose of studying family formation and childbearing. The sample size included 10,003 men and women aged 18-34 completed years, in couples and singles, plus a small number of spouses beyond the upper age limit. The sample was representative by age, marital status and region. The draw was based on mixed information from the population census carried out in the preceding year and the civil registration system existing in Bulgaria. The upper limit of the age span was selected so that the major events referring to family formation should have taken place by that age.

The following basic question was used for the measurement of intentions: 'Do you intend to have a (another) child during the next 2 years?' For pregnant women, the question is continued: '...besides the one you are expecting?'. The question is formulated separately for respondents without children and for respondents who have at least one child. An answer is selected among four items: 'Definitely yes; probably yes; probably not; definitely not'. During the analyses, I encountered problems with small numbers when this four-scale answer was used; to avoid these problems, a dichotomised system was used, by collapsing 'definitely yes' and 'probably yes' into 'rather yes', and 'definitely no' and 'probably no' into 'rather no'. The category 'rather yes' is also termed as 'strong intentions' and the category 'rather no' as 'weak intentions'.

Subsequent births became available through two sources. The survey was repeated in 2005, with an attrition rate of about 25\%. Additional information became available from register data, which inform about vital events such as changes in marital status or births for nearly all participants in the first wave (missing vital events for those who left the country). I used the register data because this information made it possible to include all respondents from the first wave in the analyses. 
According to the TPB, childbearing intentions refer to proceptive behaviour (Miller and Pasta 1994, 1995). Proceptive behaviour can be the pursuit of pregnancy, or the quest for an adoption, or the quest to improve one's reproductive health. An intention to have a child can be considered as realised, therefore, when proceptive behaviour is initiated. However, with the data at hand, we cannot measure the latter. As generally accepted in demographic research, childbearing is used as proxy, although a birth of a child is an outcome of proceptive behaviour. In the present analysis, a birth of a child during the 3 years following the first wave was accepted as a measure of the fulfilment of an intention to have a child in 2 years. One year was added to account for the unmeasured proceptive behaviour that resulted in pregnancies. Realisation thus measured does not perfectly fit the requirements of actual behaviour measurement. The caveat is that proceptive behaviour is approximated with actual births, and some births might be the result of unintended pregnancies. The variable used is dichotomous (had at least one child 3 years later or did not have a child 3 years later).

Respondents who declared with certainty that they are physically unable to have children were excluded from the analyses.

I used two explanatory ${ }^{1}$ variables, measured at the time of the first wave. The first one, for brevity named 'studying' variable, includes three states: 'is currently studying', 'intends to start studying during the next 2 years' and 'is neither studying nor intending to study during the next 2 years'. The type of studies is not specified. The second variable, named 'employment', is analogous with respect to employment: 'is currently employed', 'intends to enter into employment during the next 2 years' and 'is neither employed nor intending to enter into employment during the next 2 years'. The kind of employment is not specified either. Both unemployed and non-employed persons were asked about intentions to enter into employment. The two types of states are not exclusive: a person can be both studying and employed at the same time. Each variable was constructed independently of the other one.

Following the analysis of fertility intentions in Bulgaria by Philipov et al. (2006), five control variables were selected:

- Age, specified in the following age groups: 18-24, 25-29 and 30 and higher

- Union status: single, married and cohabiting. Apparently single individuals are less likely to have intentions for a child during the next 2 years.

- Number of siblings: 0,1 and 2 or more. It is a proxy for the impact that the family milieu might have on the formation of the intended family size; a larger family size may invoke an earlier quest for having children and hence may influence short-term intentions.

- Educational level, specified in the following three groups: lower than secondary, completed secondary and completed higher than secondary. Higher education is a proxy for a higher personal income as well as for a stronger quest towards personal expression and autonomy, particularly among women.

- Household income per household member. Quartiles were used.

\footnotetext{
${ }^{1}$ I use the term 'explanatory' here to mean 'study' variables because one of the variables of interest refers to studying.
} 
The variables for age, education and household income are quantified in groups and therefore allow for a non-linear association with the dependent variable in a regression model.

I apply logistic regression models for the analysis of the association between childbearing intentions and the diverse states related to studying or employment, i.e. for the examination of Line (g) in Fig. 1. A logistic regression model is used to investigate the direct impact of the states related to study or employment on childbearing, without the inclusion of childbearing intentions as an intermediary variable [Line (i)].

In order to examine the effect of the two competing intentions or the relevant behaviours on the realisation of childbearing intentions, I make use of the interaction between an explanatory variable and the variable for childbearing intentions as follows. First a logistic regression model is used with a dependent variable denoting whether the respondent had a child 3 years later, with an interaction between the variables for the states related to 'studying' and for the childbearing intentions, along with the control variables. Next, I make use of the following general formula for the cumulative logistic distribution function:

$$
F(u)=1 /\left(1+\exp \left(-\left(\beta_{1} x_{1}+\beta_{2} x_{2}+\beta_{12} x_{1} x_{2}+X \beta\right)\right)\right),
$$

where $F(u)$ denotes the probability that the person will have a child during the next 3 years, $\beta_{1}$ is the coefficient of the variable for childbearing intentions, $\beta_{2}$ is the coefficient of the explanatory variable for studying, $\beta_{12}$ is the coefficient of the interaction variable and $X \beta$ is the sum of the mean of each control variable multiplied by the corresponding coefficient. Thus, $X \beta$ is a constant. I experimented with other values for this constant, for example, taking those values of each of the control variables which would give either the minimum or the maximum of the constant. Then, I reran the models with different values for the constant and found that the results did not differ considerably with respect to the purposes of this article. For this reason, the results reported here refer only to the case when the constant is estimated with the means of each one of the control variables.

In our case, the variable $x_{1}$ is dichotomous (with values 0 denoting the intention to 'rather not', and 1 denoting the intention to 'rather yes', have a child during the next 2 years), and the variable $x_{2}$ has three states (in the case of the 'studying' variable, with values 0 denoting 'is neither studying nor intends to study', 1 denoting 'intends to start studying' and 2 denoting 'is currently studying'). Then $F(u)$ can be estimated for each combination of the values of $x_{1}=0$ and $x_{1}=1$ and $x_{2}=0, x_{2}=1$ or $x_{2}=2$. For example, $F\left(u ; x_{1}=1, x_{2}=1\right)$ denotes the probability that a person who had strong childbearing intentions and was intending to start studying, will have a child 2 years later. Analogously, $F\left(u ; x_{1}=1, x_{2}=0\right)$ is the probability that a person who had strong intentions to have a child and neither had an intention to start studying nor was studying at the time of survey will actually have a child 2 years later. I examine the difference

$$
F\left(u ; x_{1}=1, x_{2}=1\right)-F\left(u ; x_{1}=1, x_{2}=0\right)
$$

which denotes the differences between the two probabilities described above. It refers to the two states of studying, for persons who had strong intentions to have a 
child. This difference will be statistically equal to zero when the intention to start studying does not have an impact on a strong intention to have a child. Analogously,

$$
F\left(u ; x_{1}=0, x_{2}=1\right)-F\left(u ; x_{1}=0, x_{2}=0\right)
$$

is the difference with respect to persons who had weak intentions to have a child, and

$$
\begin{aligned}
& F\left(u ; x_{1}=1, x_{2}=2\right)-F\left(u ; x_{1}=1, x_{2}=0\right) \\
& F\left(u ; x_{1}=0, x_{2}=2\right)-F\left(u ; x_{1}=0, x_{2}=0\right)
\end{aligned}
$$

have similar interpretations for the state of currently studying, instead of intending to start studying.

Equations $2 \mathrm{a}, 2 \mathrm{~b}, 3 \mathrm{a}$ and $3 \mathrm{~b}$ were also estimated for $x_{2}$ being the 'employment' variable where the states are denoted with value 0 for 'is neither employed nor intends to enter into employment', 1 for 'intends to enter into employment' and 2 for 'is currently employed'.

These differences were used to test Hypotheses (2A), (2B) and (5A), (5B). All analyses were carried out separately for men and women, and separately for intentions to have a first and a second child. All estimates were done using Stata ${ }^{\circledR}$ and its code for estimations of non-linear combinations of estimators.

The differences apparently reflect interactions between the 'studying' or the 'employment' variable on one side and the variable for the childbearing intentions on the other. I note that the usual inclusion of an interaction variable in a logistic regression model is not an appropriate procedure in this analysis. The interaction effect is defined as the partial derivative of $F(u)$ with respect to $x_{1}$ and $x_{2}$, i.e. as $\frac{\partial F}{\partial x_{1} \partial x_{2}}$ which is apparently different from the marginal effect of the interaction variable (the latter equals $\beta_{12}$ ). The interaction effect has to be estimated additionally, and I have described one possible procedure above. Norton et al. (2004) give more details.

\section{Descriptive Analyses}

Table 1 presents distributions of the respondents by study state and certainty of intentions (the group 'rather yes' being of higher certainty than the group 'rather no'). The first block of three rows informs about the percentage distributions of 2,324 men and 1,641 women by certainty of intentions to have a first child within each one of the three study states. Thus, $35 \%$ of the men who are neither studying nor intend to start studying have declared a strong intention to have a child during the next 2 years. This percentage is considerably lower for men who are studying or intend to start studying. A similar distribution is observed for the women.

The second block gives the percentage distribution of men and women among the three states related to studying, for each level of certainty of the intention to have a child. Among the men who stated they would rather have than not have a child during the next 2 years, $78 \%$ were in the state of neither intending to start studying nor currently studying, while the percentages for the remaining two states are $11 \%$ 
Table 1 Distribution of male and female respondents by study state and intentions to have a first or a second child, 2002

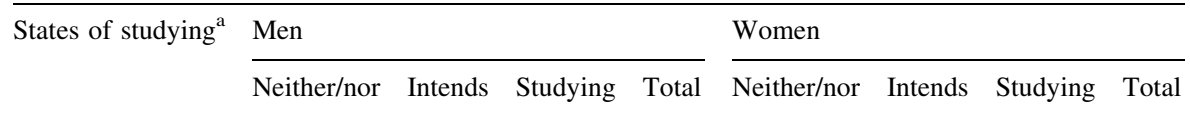

Intends a first child

Percent, by level of certainty of intentions

$\begin{array}{lrrrrrrrr}\text { Rather yes (\%) } & 35 & 21 & 15 & 29 & 49 & 30 & 27 & 39 \\ \text { Rather no (\%) } & 65 & 79 & 85 & 71 & 51 & 70 & 73 & 61 \\ \text { Total (\%) } & 100 & 100 & 100 & 100 & 100 & 100 & 100 & 100\end{array}$

Percent, by studying state

\begin{tabular}{|c|c|c|c|c|c|c|c|c|}
\hline Rather yes (\%) & 78 & 11 & 11 & 100 & 64 & 17 & 19 & 100 \\
\hline Rather no (\%) & 59 & 17 & 24 & 100 & 42 & 24 & 34 & 100 \\
\hline All (\%) & 65 & 15 & 20 & 100 & 51 & 21 & 28 & 100 \\
\hline \multicolumn{9}{|c|}{ Jumber of observations } \\
\hline Rather yes & 529 & 75 & 72 & 676 & 407 & 106 & 124 & 637 \\
\hline Rather no & 974 & 278 & 396 & 1,648 & 422 & 244 & 338 & 1,004 \\
\hline All & 1,503 & 353 & 468 & 2,324 & 829 & 350 & 462 & 1,64 \\
\hline
\end{tabular}

Intends a second child

Percent, by level of certainty of intentions

$\begin{array}{lrrrrrrrr}\text { Rather yes (\%) } & 38 & 59 & 49 & 40 & 32 & 40 & 38 & 34 \\ \text { Rather no (\%) } & 62 & 41 & 51 & 60 & 68 & 60 & 62 & 66 \\ \text { Total (\%) } & 100 & 100 & 100 & 100 & 100 & 100 & 100 & 100\end{array}$

Percent, by studying state

\begin{tabular}{|c|c|c|c|c|c|c|c|c|}
\hline Rather yes (\%) & 87 & 9 & 4 & 100 & 77 & 14 & 9 & 100 \\
\hline Rather no (\%) & 93 & 4 & 3 & 100 & 81 & 11 & 8 & 100 \\
\hline All (\%) & 91 & 6 & 3 & 100 & 80 & 12 & 8 & 100 \\
\hline \multicolumn{9}{|c|}{ Number of observations } \\
\hline Rather yes & 472 & 48 & 21 & 541 & 409 & 76 & 49 & 534 \\
\hline Rather no & 755 & 33 & 22 & 810 & 851 & 116 & 79 & 1,046 \\
\hline All & 1,227 & 81 & 43 & 1,351 & 1,260 & 192 & 128 & 1,580 \\
\hline
\end{tabular}

Note: Totals may differ slightly from those in Table 2 because of differences in non-responses

a The complete names of the three states of studying are as follows: 'Neither studying nor intending to do so', 'Intends to start studying' and 'Currently studying'

each. Women who are currently studying or intend to study are more inclined to have a child in 2 years than men (19 and 17\% correspondingly).

When intentions for having a second child are considered, it is striking to find that the number of men who intend to start studying or are currently studying is very low: 81 and 33, respectively, out of 1,351. The distributions indicate that the relevant percentages are considerably higher when compared to men's intentions to have a first child. A similar inference can be made for the women where the numbers are not as small. 
Table 2 Distribution of male and female respondents by employment state and intentions to have a first or a second child, 2002

\begin{tabular}{llllll}
\hline $\begin{array}{l}\text { States of } \\
\text { employment }\end{array}$ & Men & & \multicolumn{2}{l}{ Women } \\
\cline { 2 - 3 } \cline { 5 - 6 } & $\begin{array}{l}\text { Neither/ Intends Employed Total } \\
\text { nor }\end{array}$ & & $\begin{array}{l}\text { Neither/ } \\
\text { nor }\end{array}$ & Intends Employed Total \\
\hline
\end{tabular}

Intends a first child

Percent, by level of certainty of intentions

$\begin{array}{lrrrrrrrr}\text { Rather yes (\%) } & 17 & 26 & 34 & 29 & 24 & 36 & 45 & 39 \\ \text { Rather no (\%) } & 83 & 74 & 66 & 71 & 76 & 64 & 55 & 61 \\ \text { Total (\%) } & 100 & 100 & 100 & 100 & 100 & 100 & 100 & 100\end{array}$

Percent, by employment state

$\begin{array}{lrrrrrrrr}\text { Rather yes (\%) } & 11 & 21 & 68 & 100 & 12 & 20 & 68 & 100 \\ \begin{array}{l}\text { Rather no (\%) } \\ \text { All (\%) }\end{array} & 21 & 24 & 55 & 100 & 25 & 23 & 52 & 100 \\ \begin{array}{l}\text { Number of observations } \\ \text { Rather yes }\end{array} & 18 & 23 & 59 & 100 & 20 & 22 & 58 & 100 \\ \text { Rather no } & 74 & 140 & 460 & 674 & 77 & 131 & 434 & 642 \\ \text { All } & 350 & 398 & 907 & 1,655 & 247 & 233 & 529 & 1,009 \\ & 424 & 538 & 1,367 & 2,329 & 324 & 364 & 963 & 1,651\end{array}$

Intends a second child

Percent, by level of certainty of intentions

\begin{tabular}{|c|c|c|c|c|c|c|c|c|}
\hline Rather yes $(\%)$ & 36 & 38 & 41 & 40 & 29 & 33 & 36 & 34 \\
\hline Rather no (\%) & 64 & 62 & 59 & 60 & 71 & 67 & 64 & 66 \\
\hline Total $(\%)$ & 100 & 100 & 100 & 100 & 100 & 100 & 100 & 100 \\
\hline \multicolumn{9}{|c|}{ Percent, by employment state } \\
\hline Rather yes (\%) & 4 & 12 & 84 & 100 & 23 & 21 & 56 & 100 \\
\hline Rather no (\%) & 4 & 14 & 82 & 100 & 28 & 22 & 50 & 100 \\
\hline All (\%) & 4 & 13 & 83 & 100 & 26 & 21 & 53 & 100 \\
\hline \multicolumn{9}{|c|}{ Number of observations } \\
\hline Rather yes & 21 & 68 & 460 & 549 & 122 & 110 & 303 & 535 \\
\hline Rather no & 37 & 112 & 668 & 817 & 297 & 228 & 529 & 1,054 \\
\hline All & 58 & 180 & 1,128 & 1,366 & 419 & 338 & 832 & 1,589 \\
\hline
\end{tabular}

Note: totals may differ slightly from those in Table 1 because of differences in non-responses

a The complete names of the three states of employment are as follows: 'Neither employed nor intending to enter into employment', 'Intends to enter into employment' and 'Employed'

Table 2 gives similar data with respect to the states related to employment. The percentage of respondents who intend to have a first child and at the same time intend to enter into employment or are employed is high both for men and for women as compared to the state of currently studying (Table 1). When intentions to have a second child are considered, there is a pronounced difference between the state of employment and of studying among the women. The percentage of employed women with strong intentions to have a child is $56 \%$ while for women currently studying it is only $9 \%$. Being employed can thus hardly be classified as a competing behaviour to childbearing. 
Table 3 Proportion of men and women who had a first or a second child towards 2005, by studying or employment state, and intentions to have a first or a second child in 2002

\begin{tabular}{|c|c|c|c|c|c|c|}
\hline & \multicolumn{3}{|l|}{ Men } & \multicolumn{3}{|l|}{ Women } \\
\hline & Neither/nor & Intends & Studying & Neither/nor & Intends & Studying \\
\hline \multicolumn{7}{|c|}{ Studying states ${ }^{\mathrm{a}}$} \\
\hline \multicolumn{7}{|c|}{ Intended a first child } \\
\hline Rather yes & 0.25 & 0.28 & 0.19 & 0.30 & 0.27 & 0.29 \\
\hline Rather no & 0.10 & 0.07 & 0.04 & 0.20 & 0.13 & 0.10 \\
\hline \multicolumn{7}{|c|}{ Intended a second child } \\
\hline Rather yes & 0.28 & 0.25 & 0.24 & 0.31 & 0.18 & 0.27 \\
\hline Rather no & 0.12 & 0.12 & 0.14 & 0.14 & 0.07 & 0.10 \\
\hline \multicolumn{7}{|c|}{ Employment states ${ }^{\mathrm{b}}$} \\
\hline \multicolumn{7}{|c|}{ Intended a first child } \\
\hline Rather yes & 0.15 & 0.25 & 0.27 & 0.32 & 0.30 & 0.29 \\
\hline Rather no & 0.03 & 0.06 & 0.11 & 0.12 & 0.17 & 0.15 \\
\hline \multicolumn{7}{|c|}{ Intended a second child } \\
\hline Rather yes & 0.19 & 0.40 & 0.26 & 0.28 & 0.36 & 0.27 \\
\hline Rather no & 0.22 & 0.15 & 0.11 & 0.15 & 0.14 & 0.11 \\
\hline
\end{tabular}

a See footnote (a) under Table 1

b See footnote (a) under Table 2

Table 3 informs about childbearing during the 3 years according to the survey in 2002. It is no surprise to find that respondents with stronger intentions were more likely to have a child during the period than respondents with weaker intentions. For example, out of 529 men, who were neither studying nor intending to start studying in 2002 and who had stronger intentions for having a first child (see Table 1), 25\% actually did have a child. Out of the 974 men, who neither studied nor intended to start studying and had weak intentions to have a first child, only $10 \%$ actually had a child. The proportion of respondents with strong intentions to have a first or a second child who actually had one is usually higher among those who were neither studying nor intending to start studying. Where employment is considered, the highest levels of childbearing are observed among respondents who intended to enter into employment, with only one exception. Thus, the study variable reveals competing intentions and behaviour with childbearing, while the employment variable rather reveals a supporting relationship.

\section{Model Results}

Table 4 displays logistic coefficients for the association between the 'studying' variable and childbearing intentions, and between the 'employment' variable and childbearing intentions. The dependent variable is the intention to have a child, with a 'success' being the option 'rather yes', i.e. the stronger intention to have a child. The models were run separately for men and women, as well as for intentions to 
Table 4 Logistic coefficients for the association between a state related to studying or employment, and intentions to have a first or a second child, 2002

\begin{tabular}{|c|c|c|c|c|}
\hline & \multicolumn{2}{|c|}{ Intend a first child } & \multicolumn{2}{|c|}{ Intend a second child } \\
\hline & Men & Women & Men & Women \\
\hline \multicolumn{5}{|l|}{ Studying state } \\
\hline No studies, no intentions (base) & 0 & 0 & 0 & 0 \\
\hline Intends to start studying & $-0.37 *$ & $-0.48 * *$ & $0.71 * *$ & 0.31 \\
\hline Currently studying & $-0.56^{* *}$ & $-0.31 *$ & 0.33 & 0.14 \\
\hline \multicolumn{5}{|l|}{ Employment state } \\
\hline No employment, no intentions (base) & 0 & 0 & 0 & 0 \\
\hline Intends to enter into employment & 0.23 & 0.32 & -0.33 & $0.42 *$ \\
\hline Currently employed & $0.51 * *$ & $0.71 * *$ & -0.72 & 0.23 \\
\hline
\end{tabular}

Control variables: age, union status, number of siblings, level of achieved education, and household income per head of the household

$* p>0.05 ; * * p>0.01$

have a first or a second child, i.e. four models for the 'studying' case and four models for the 'employment' case. Control variables were used; the coefficients for these variables are not included in the table. The associations are described by Line (g) in Fig. 1 and hence refer to Hypotheses (1A), (1B), (4A) and (4B).

The association between the intention to have a first child and either intending to start studying or currently studying is negative and statistically significant. Respondents in these states are less likely to construct strong intentions for having a child than respondents who were neither studying nor intending to start studying. In the case of intending a second child, the association is significant only for men who intended to start studying, and it is - unexpectedly-positive. This result needs further investigation; I recall that the number of observations in this case is very small, as shown in Table 1. The conclusion is that Hypotheses (1A) and (1B) hold for men and women who intend to have a first child within the next 2 years. An intention to start studying hampers the intention to enter parenthood; so does the behaviour of currently studying.

The association between being employed and intentions to have a first child is positive and statistically significant for men as well as for women. Hence, being employed is a behaviour that supports the construction of an intention to enter into parenthood. Hypothesis (4B) holds for men but not for women, where a negative association was expected. Intentions to enter into employment associate positively with childbearing intentions for women who intend to have a second child. This finding is the inverse of what is stated in Hypothesis (4A) for women. No other statistically significant association was found; therefore Hypothesis (4A) cannot be accepted for an intended second child.

Table 5 gives the logistic coefficients for a logistic regression model where the dependent variable is 'had a child during the next 3 years'. Note that the period of 3 years, and not 2 years, was selected to capture conceptions initiated during the last 9 months of the 2-year period. All variables are included without interactions. 
Table 5 Logistic coefficients for the dependent variable 'had a child towards end of 2005'; explanatory and control variables observed in 2002

\begin{tabular}{|c|c|c|c|c|}
\hline & \multicolumn{2}{|l|}{ First child } & \multicolumn{2}{|c|}{ Second child } \\
\hline & Men & Women & Men & Women \\
\hline \multicolumn{5}{|l|}{ Explanatory variables } \\
\hline \multicolumn{5}{|l|}{ Intentions to have a child } \\
\hline 'Rather not' (base) & 0 & 0 & 0 & 0 \\
\hline 'Rather yes' & $0.83 * * *$ & $0.66 * * *$ & $1.15^{* * *}$ & $1.17 * * *$ \\
\hline \multicolumn{5}{|l|}{ Studying state ${ }^{a}$} \\
\hline Neither/nor (base) & 0 & 0 & 0 & 0 \\
\hline Intends & -0.15 & $-0.31 *$ & -0.04 & $-0.66 * *$ \\
\hline Studying & $-0.51 * *$ & $-0.46^{* *}$ & -0.01 & -0.17 \\
\hline \multicolumn{5}{|l|}{ Employment state $^{\mathrm{b}}$} \\
\hline Neither/nor (base) & 0 & 0 & 0 & 0 \\
\hline Intends & 0.41 & 0.05 & 0.24 & $0.32 *$ \\
\hline Employed & $0.67 * * *$ & 0.03 & 0.20 & $0.36^{*}$ \\
\hline \multicolumn{5}{|l|}{ Control variables } \\
\hline \multicolumn{5}{|l|}{ Age } \\
\hline $18-24$ & $0.66^{* * *} *$ & $0.52 * * *$ & $0.50 * *$ & $1.25^{* * *}$ \\
\hline $25-29$ & $0.66^{* * *}$ & 0.29 & $0.56^{* * *}$ & $0.82 * * *$ \\
\hline $30+($ base $)$ & 0 & 0 & 0 & 0 \\
\hline \multicolumn{5}{|l|}{ Siblings } \\
\hline None (base) & 0 & 0 & 0 & 0 \\
\hline One & $0.55^{* *}$ & 0.03 & $0.48^{*}$ & -0.11 \\
\hline Two & $0.48^{*}$ & 0.30 & $0.66^{* *}$ & -0.22 \\
\hline \multicolumn{5}{|l|}{ Union status } \\
\hline Single & $-1.50 * * *$ & $-0.92 * * *$ & -0.56 & 0.17 \\
\hline Married (base) & 0 & 0 & 0 & 0 \\
\hline Cohabiting & 0.04 & 0.01 & 0.30 & $0.36^{*}$ \\
\hline \multicolumn{5}{|l|}{ Education } \\
\hline Lower than Sec. & $0.44 * *$ & -0.10 & $0.77 * * *$ & $0.67 * * *$ \\
\hline Secondary & 0 & 0 & 0 & 0 \\
\hline Higher than Sec. & -0.10 & 0.05 & 0.31 & $0.40 * *$ \\
\hline \multicolumn{5}{|l|}{ Household income } \\
\hline Lowest quartile (base) & 0 & 0 & 0 & 0 \\
\hline 2nd quartile & -0.28 & -0.16 & $-0.49 *$ & $-0.73 * * *$ \\
\hline 3rd quartile & 0.06 & -0.06 & $-0.57 * *$ & $-0.63 * *$ \\
\hline 4th quartile & 0.11 & -0.22 & -0.30 & $-0.41 *$ \\
\hline$N$ & 2197 & 1541 & 1305 & 1482 \\
\hline
\end{tabular}

$* p>0.10 ; * * p>0.05 ; * * * p>0.01$

a See footnote (a) under Table 1

b See footnote (b) under Table 2 
The model coefficients reflect associations described by Line (i) in Fig. 1 and reflected in Hypotheses (3A), (3B), (6A) and (6B).

The first explanatory variable refers to childbearing intentions. It is no surprise to find that a stronger intention to have a child is more likely to be realised than a weaker intention. In the case of the states related to the intentions to start studying or currently studying, all coefficients are negative. Women's intentions to start studying are statistically significant in their negative impact on the subsequent actual childbearing of either a first or a second child. Hence, for women, Hypothesis (3A) holds for the birth of a first and of a second child.

The actual behaviour of currently studying relates negatively for men's and women's actual entry into parenthood. Hypothesis (3B) holds and actually studying is indeed a competing behaviour with entry into parenthood for both men and women.

For women, both the intention to enter into employment and the behaviour of being employed associate positively with the birth of a second child. Hence Hypotheses (6A) and (6B) hold for women with respect to the birth of a second child in the same way as they were formulated for men. That is, intended as well as actual employment facilitates, rather than hampers the birth of a child. This unexpected finding can be explained in variety of ways and needs more elaboration. Hypothesis (6B) holds for men's entry into fatherhood, where being employed is considered: men's income is of importance for their entry into parenthood.

The demographic control variables have an effect on childbearing, as could be expected: having a child is less likely for single persons and for older persons. The gender difference in the impact of the number of siblings is unexpected; it requires a specific analysis. Lower educated persons are more likely to have a child during the next 3 years than those with higher education, and women with secondary education are less likely to have their second child during the next 3 years as compared to women with a different educational level. The impact of household income is most pronounced among women having a second child.

Finally, Table 6 displays the estimated differences of the probabilities for having a child at different levels of the childbearing intention, and by intentions to start studying or employment, or the actual behaviours of currently studying or being in employment. The differences were estimated with the application of Eqs. 2a, 2b and 3a, 3b. They inform about associations along Line (h) in Fig. 1 and are used to evaluate Hypotheses (2A), (2B), (5A), and (5B). As an illustration, consider the stronger intentions for having a first child. In this case, the difference between the probabilities relating to the states of 'intends to start studying' and 'is neither studying nor intends to do so' is estimated using Eq. 2a; it is 0.03 for men and lower than 0.01 ( 0.00 in the table) for women, apparently statistically insignificantly different from 0 .

The same difference is significantly different from 0 for women's weaker intentions to have a first child. It is negative and, thus, shows that the intention to start studying has a competing effect on the realisation of the intention to have a first child, when that intention was weak. Hypothesis (2A) holds for women's entry into motherhood. The intention to start studying has a significant competing effect on the realisation of women's intention to have a second child, for both a strong and a 
Table 6 Estimated differences of the predicted probabilities for having a first or a second child towards 2005 , by state of studying or employment and intentions to have the child in 2002

\begin{tabular}{lllll}
\hline Differences & First child & & Second child & \\
\cline { 2 - 3 } \cline { 5 - 6 } & Men & Women & Men & Women \\
\hline
\end{tabular}

Studying states ${ }^{\mathrm{a}}$

B/n 'intends' and 'neither/nor', when respondent's intentions for a child were...

$\begin{array}{lrrrr}\ldots \text { Stronger } & 0.03 & 0.00 & -0.03 & -0.10^{*} \\ \ldots \text { Weaker } & -0.04 & -0.10^{* * *} & 0.01 & -0.07 * * *\end{array}$

B/n 'studying' and 'neither/nor', when respondent's intentions for a child were...

$\begin{array}{lllrr}\ldots \text { Stronger } & -0.02 & -0.02 & -0.02 & -0.03 \\ \ldots \text { Weaker } & -0.08^{* * *} & -0.13^{* * * *} & 0.03 & -0.03\end{array}$

Employment states ${ }^{\mathrm{b}}$

B/n 'intends' and 'neither/nor', when respondent's intentions for a child were...

\begin{tabular}{|c|c|c|c|c|}
\hline Stronger & 0.09 & -0.04 & $0.19 *$ & $0.15^{* *}$ \\
\hline Weaker & 0.05 & 0.02 & -0.06 & 0.00 \\
\hline
\end{tabular}

B/n 'employed' and 'neither/nor', when respondent's intentions for a child were...

$\begin{array}{llrrr}\ldots \text { Stronger } & 0.07 & -0.04 & 0.12^{\#} & 0.08^{\#} \\ \ldots \text { Weaker } & 0.10^{* *} & 0.02 & -0.04 & 0.04\end{array}$

$* p>0.10 ; * * p>0.05 ; * * * p>0.01 ;{ }^{*} p>0.12$

${ }^{a}$ See footnote (a) under Table 1

b See footnote (a) under Table 2

weak childbearing intention. Hypothesis (2A) holds again, although no support is found for the strength of the childbearing intention. This hypothesis does not hold for men.

In the case of the actual behaviour of currently studying at the time of measurement of childbearing intentions, the differences in the predicted probabilities are statistically significant for both men and women, where a first child and weaker childbearing intentions are considered. Hypothesis (2B) is confirmed for entry into parenthood. No support is found for its validity for the birth of a second child.

Where intentions to enter into employment are considered, the differences in the predicted probabilities to have a second child show a positive effect on childbearing for women and men with stronger childbearing intentions. The same is observed for the state of being currently employed, although statistical significance is compromised at a high $p$ value. For men, Hypothesis (5A) finds support for the realisation of intentions for a second child. For women, the hypothesis holds in the same way as for men, i.e. the intention to enter into employment facilitates, instead of hampers, the realisation of a stronger childbearing intention, relative to those who do not intend to change their employment state.

Statistical significance is observed also for the realisation of the intention to have a first child among employed men, which is in line with Hypothesis (5B). No support is found for this hypothesis in the case of women, and no support was found for the validity of Hypothesis (5A) for entry into parenthood. 


\section{Summary and Discussion}

Based on the theoretical discussion, I formulated three statements placed in the beginning of the section entitled 'Hypotheses'. While they are expected to hold for any competing or supporting intention or behaviour, they were tested for intentions and actual behaviour related to studying and employment. The hypotheses were checked in the contextual environment of Bulgaria. Their validity was found to be specific by gender and order of intended birth (and particularly for entry into parenthood and for having a second child). The summary is presented first for the states related to studying and next for those related to employment.

(I) States related to studying

- The intention to have a first child as well as the corresponding behavioural outcome of having that first child, are subject to the competing effect of the intention to start studying as well as of actually studying. This inference is valid for men and for women. For women, a weaker intention to enter into motherhood is more likely to remain unrealised than a stronger intention under the presence of the competing intention to start studying.

- The intention to have a second child and the corresponding behavioural outcome of having that second child are subject, among women only, to the competing effect of the intention to start studying.

In general, the intention to start studying competes with the intention to have a child and hampers its realisation. Analogously, the behaviour of currently studying competes with childbearing intentions and their realisation. These effects are more pronounced when childbearing intentions are weaker. These findings show that when the interest is in the effect of 'study states' on childbearing intentions and behaviour, all respondents can be distributed in three main groups with respect to their state of studying: those who are currently studying, those who intend to start studying, and those who are neither studying nor intend to do so. This grouping is an extension of the pioneering work of Blossfeld and Huinink (1991) which rested on two states: being in a study course and not being in a study course. The results reported here show that two of the three groups can be aggregated, namely those who are studying and those who intend to start studying. This two group divisions differ significantly from the one based on behaviour only, at least where short-term timing of intended childbearing is considered.

\section{(II) States related to employment}

- For men, the intention to have a first child and the subsequent behavioural outcome of having that first child are facilitated by the state of being employed at the time of construction of the intention. Men's weaker childbearing intentions are encouraged by the facilitating behaviour of being employed.

- Women's intention to have a second child and the subsequent behavioural outcome of having that second child are facilitated by intentions to enter into employment. Both men's and women's stronger childbearing intentions are encouraged in their realisation by intended or actual employment. Women's actual birth of a second child is facilitated when being employed. 
An intention to enter into employment or the behaviour of being employed support the formation of an intention to have a child and its subsequent realisation (although in a slightly different way for men and for women). This finding is expected for men whose opportunity costs are low in the Bulgarian context. However, it is surprising for women, given the widely recognised conflict between work for pay and childrearing: if the behaviours are incompatible, the corresponding intentions should be competing, not supporting.

One potential explanation is indicated by the variable for household income (Table 5) which shows that women in poorer households are more likely to have a child 3 years later (a similar association was observed between household income and childbearing intentions for women, not included in Table 3). In 2002, the transition to an advanced market economy was still proceeding in Bulgaria. Personal income is considerably differentiated and in a large number of families both partners need to work to assure a household income at reasonable levels. This particularly manifests when there is already one child present in the family. A family that wants to have a second child needs to strive for a higher income to support the fourth family member, and an unemployed woman is likely to intend to enter into employment. In addition, the rising opportunity costs are compensated partially by child allowances and other instruments of the family policy (see Koytcheva and Philipov 2008, who provide a description of Bulgarian family policy). Child allowances were moderate at the time of the survey and would have been of relative importance mainly to persons with low income. Therefore, employed women with low income are more likely to have children than employed women with a higher income, because low child allowances matter more when income is low. Child allowances were especially low for unemployed women, which stimulated these women to enter into employment before having a (second) child.

More elaboration is needed on this unexpected and important finding. Another potential explanation is that multiple role involvement can be rewarding for specific groups of women (Moors 2008, p. 37, discusses particularly the roles of being employed and doing household work).

This analysis of childbearing intentions and behaviour, expanded to include the effect of other intentions and behaviour, complements the one that centres on competing attitudes to childbearing, as elaborated by Barber (2001). The findings show that intentions to start studying compete with childbearing intentions, just like the corresponding behaviours compete. Persons who intend to start studying construct childbearing intentions and subsequently behave in a similar manner to those who are already studying. Therefore, the contrast with respect to studying is not based on the actual behaviour of currently studying, but on the group of those who intend to start studying or already do so on one side, and those who are neither studying nor intending to do so on the other. It is preferable to use this alternative contrast when the state of studying is included in models for fertility analyses.

Acknowledgements This research was carried out within the project 'Fertility intentions and outcomes: The role of policies to close the gap' supported by the European Commission, DG 'Employment, Social Affairs and Equal Opportunities' (Contract Number: VS/2006/0685). Max Planck Institute for Demographic Research provided the survey data. I acknowledge the helpful comments to an earlier draft by A. Liefbroer and J. Barber, as well as the thoughtful reviews of anonymous referees. 


\section{References}

Ajzen, I. (1991). The theory of planned behavior. Organizational Behavior and Human Decision Processes, 50, 179-211.

Ajzen, I., \& Fishbein, M. (2005). The influence of attitudes on behavior. In D. Albarracín, B. T. Johnson, \& M. P. Zanna (Eds.), The handbook of attitudes (pp. 173-221). Mahwah, NJ: Erlbaum.

Anttonen, A., \& Sipilä, J. (1996). European social care services: is it possible to identify models? Journal of European Social Policy, 6(2), 87-100.

Barber, J. (2001). Ideational influences on the transition to parenthood: attitudes towards childbearing and competing alternatives. Social Psychology Quarterly, 64(2), 101-127.

Barber, J., \& Axinn, W. (2005). How do attitudes shape childbearing in the United States? In A. Booth \& A. Crouter (Eds.), The new population problem (why families in developed countries are sinking and what it means). Mahwah, New Jersey, London: Lawrence Erlbaum Associates Publishers.

Barber, J., Axinn, W., \& Thornton, A. (2002). The influence of attitudes on family formation processes. In $\mathrm{R}$. Lesthaeghe (Ed.), Meaning and choice value orientations and life course decisions. Brussels/The Hague: NIDI/CBGS Publications.

Billari, F., \& Philipov, D. (2004). Education and the transition to motherhood: A comparative analysis of Western Europe. European Demographic Research Papers No. 3. Vienna: Vienna Institute of Demography.

Billari, F., Philipov, D., \& Testa, M. R. (2009). The proximate antecedents of fertility intentions: An application of the theory of planned behaviour in the case of Bulgaria. European Journal of Population. doi: 10.1007/s10680-009-9187-9.

Blossfeld, H.-P., \& Huinink, J. (1991). Human capital investments or norms of role transition? How women's schooling and career affect the process of family formation. American Journal of Sociology, 97, 143-168.

Blossfeld, H.-P., Klijzing, E., Mills, M., \& Kurz, K. (Eds.). (2005). Globalization, uncertainty and youth in society. London: Routledge.

Corijn, M., \& Klijzing, E. (Eds.). (2001). Transitions to adulthood in Europe (Vol. 10). Dordrecht: Kluwer.

Esping-Andersen, G. (1999). Social foundations of postindustrial economies. Oxford: Oxford University Press.

Festinger, L. (1957). A theory of cognitive dissonance. Stanford, CA: Stanford University Press.

Gauthier, A. (2007). Becoming a young adult: An international perspective on the transitions to adulthood. European Journal of Population, 23, N3-4, special issue, 217-223.

Koytcheva, E. (2006). Social-demographic differences in fertility and family formation in Bulgaria before and after the start of the societal transition. Rostock: University of Rostock.

Koytcheva, E., \& Philipov, D. (2008). Bulgaria: Ethnic differentials in rapidly declining fertility. Demographic Research, 19, article 13, http:/www.demographic-research.org/volumes/vol19/13/.

Liefbroer, A. (2009). Changes in family size intentions across young adulthood: A life-course perspective. European Journal of Population, doi: 10.1007/s10680-008-9173-7.

Miller, W. B., \& Pasta, D. J. (1994). The psychology of child timing: A measurement instrument and a model. Journal of Applied Social Psychology, 24, 218-250.

Miller, W. B., \& Pasta, D. J. (1995). Behavioural intentions: Which ones predict fertility behaviour in married couples? Journal of Applied Social Psychology, 25, 530-555.

Moors, G. (2008). The valued child. In search of a latent attitude profile that influences the transition to motherhood. European Journal of Population, 24(1), 33-57.

Mulder, C., \& Smits, J. (1999). First-time home-ownership of couples: The effect of inter-generational transmission. European Sociological Review, 15(3), 323-337.

Norton, E., Wang, H., \& Ai, C. (2004). Computing interaction effects and standard errors in logit and probit models. The Stata Journal, 4(2), 154-167.

Philipov, D., Spéder, Z., \& Billari, F. (2006). Soon, later, or ever? The impact of anomie and social capital on fertility intentions in Bulgaria (2002) and Hungary (2001). Population Studies, 60(3), 289-308.

Quesnel-Vallée, A., \& Morgan, S. P. (2003). Missing the target? Correspondence of fertility intentions and behavior in the U.S. Population Research and Policy Review, 22(5-6), 497-525.

Rindfuss, R., \& Brauner-Otto, S. (2008). A review of policies and practices related to the "highest-low" fertility in Sweden. Vienna Yearbook of Population Research, 57-88. 
Schoen, R., Astone, N. M., Kim, Y. J., \& Nathanson, C. A. (1999). Do fertility intentions affect fertility behaviour? Journal of Marriage and the Family, 61(3), 790-799.

Symeonidou, H. (2000). Expected and actual family size in Greece: 1983-1997. European Journal of Population, 16, 335-352.

Testa, M. R., \& Toulemon, L. (2006). Family formation in France: Individual preferences and subsequent outcomes. Vienna Yearbook of Population Research, 2006, 41-75.

Thomson, E., \& Brandreth, Y. (1995). Measuring fertility demand. Demography, 34, 343-354. 